\title{
Appropriate Complementary Feeding Practices and Associated Factors Among Caregivers of Children Age 6-23 Months in Rural Areas of Hunan Province, China: A Community-based Cross-sectional Study
}

Minghui Liao

Maternal and Child Health Hospital of Hunan Province https://orcid.org/0000-0003-0184-5702

Qun Huang

Maternal and Child Health Hospital of Hunan Province

Huixia Li

Maternal and Child Health Hosipital of Hunan Province

Yi Liao

Maternal and Child Health Hosipital of Hunan Province

Guangwen Huang ( $\sim$ debbie0@msn.cn)

Maternal and Child Health Hospital of Hunan Province https://orcid.org/0000-0001-7593-0235

\section{Research article}

Keywords: Infants and Young Children, Cross-sectional Study, Complementary Feeding

Posted Date: October 29th, 2020

DOI: https://doi.org/10.21203/rs.3.rs-98306/v1

License: (c) (1) This work is licensed under a Creative Commons Attribution 4.0 International License.

Read Full License 


\section{Abstract}

Background

This study aimed to evaluate the quality and associated factors that potentially influence complementary feeding practices among Chinese caregivers living in Hunan, a rapidly developing province in China.

Methods

Three indicators( minimum dietary diversity(MDD), minimum meal frequency(MMF) and minimum acceptable diet(MAD)) were used to evaluate the rationality of complementary feeding. A multi-factor unconditional logistic regression model was employed to analyzeanalyse the relevant factors of complementary feeding.

Results

The eligibility rates of MDD, MMF and MAD for children aged 6-23 months were $62.3 \%, 75.1 \%$ and $44.0 \%$, respectively. The ineligible OR values of MDD for children aged 12-17 and 18-23 months were 0.238 and 0.103 , respectively, and those of MAD were 0.425 and 0.376 , respectively, compared with those for children aged 6-11 months. Compared children whose mothers moved out for work, the ineligible MMF for children whose mothers were not migrant workers was 2.069. Compared with parents who scored less than 60 in knowledge and attitude towards nutrition and health, the ineligible OR values of MDD, MMF and MAD for children whose parents obtained $60-79$ were $0.653,0.689$ and 0.668 , respectively, and those for children whose parents obtained $80-100$ were $0.543,0.428$ and 0.496 , respectively (all P values $<0.05$ ).

Conclusion

The complementary feeding of children in rural areas of Hunan Province needs to be improved. Younger month-age, mothers' not going out to work and parents' lacking in knowledge about nutrition and health are high risk factors for poor complementary feeding.

\section{What Is Already Known On This Topic}

1. Malnutrition is still a severe health problem for children. The period of supplementary feeding is the critical period for malnutrition.

2. Complementary feeding will affect the growth and development of children.

3. Studies have shown that children age, family income, caregiver's education level, occupation and feeding knowledge can affect children's complementary feeding.

\section{What This Paper Adds}

1. This study describes the current status of complementary food supplements in rural China. 
2. This is a Well-conducted study on influencing factors of complementary feeding for children aged 623 months in rural areas of China, including cultural and socio-economic factors.

3. It provides a basis for improving the situation of infant supplementary feeding in rural areas of China.

\section{Background}

Malnutrition in children is a global public health problem. About 144 million children under 5 suffer from stunting, and 47 million are diagnosed with wasting[1]. In low-and-middle-income countries, undernutrition is the main cause of death ${ }^{2]}$ among $45 \%$ of children under 5 . For surviving children, undernutrition will also cause lasting damage to their neurodevelopment and cognition, increasing the risk of chronic diseases, and affecting their labour and income in their adulthood[3].

Undernutrition is also a major health problem among Chinese children. According to the Report of Nutrition and Development for Children in China, the rates of underweight, stunting and wasting among children under 5 are $3.6 \%, 9.9 \%$ and $2.3 \%$, respectively, which are lower than in most developing countries and significantly lower than in Southeast Asian countries but higher than in developed countries, such as the United States.

In the complementary feeding period of 6-23 months of age, children can only eat a small amount of food due to their small stomach capacity. Thus, complementary food must be rich in energy and nutrient density, and reasonable feeding frequency is required to meet the needs of physical growth and brain development of children. Appropriate complementary feeding can promote the growth and development of children, while belated and unreasonable complementary feeding may lead to stunting ${ }^{[4]}$. Therefore, ensuring adequate complementary food for children aged 6-23 months is critical for achieving the global development goal of reducing the number of undernourished people from 171 million in 2010 to 100 million by $2025^{[5]}$.

Research on factors related to complementary feeding in other regions has shown that highly educated parents, wealthy families, acceptance of media publicity, adequate pre-and post-natal education, gender and age of children, number of family members, deliveries at health facilities, low pregnancy frequency, occupations of gravida, urban areas, knowledge of complementary feeding and acceptance of feeding advice while immunisation are the decisive factors $^{[6-9]}$.

Surveys were conducted in China, but the evidence on specific predictive factors (including cultural and socioeconomic factors) of complementary feeding is still limited. Therefore,this work investigated the status of complementary feeding of rural children in Hunan Province. Indicators for Assessing Infants and Young Child Feeding Practices (WHO) was used for analysis to understand the feeding status and existing problems of rural children in Hunan Province. Results can provide basis for establishing feeding programs for children in this area and other similar areas. 


\section{Materials And Methods}

\subsection{Respondents}

Multi-stage stratified random sampling was used to select 24 sites (12 streets and 12 towns) in 6 cities of Hunan Province. Approximately 50 children aged 6-23 months and their caregivers were selected from each survey spot, with a total of 1,200 participants (the actual number was 1,220).

\subsection{Contents and methods}

A self-designed questionnaire was employed to conduct preliminary experiments to ensure high compliance. The contents mainly included children's basic information, condition of childbirth, feeding status, health states and diet retrospective investigation. The parents' feeding method, related knowledge and attitude towards nutrition and health were also included. The method of investigation was face-toface interview between investigators and caregivers.

\subsection{Quality control}

A unified questionnaire was used. Investigators with medical background were intensively trained to familiar with the questionnaire before formal investigation. The process was supervised and guided by the main staff from the beginning to the end to ensure timely correction for any problems.

\subsection{Related indicators and their definitions}

According to Indicators for Assessing Infant and Young Child Feeding Practices, the main analysis indicators included the following: (1)Minimum Dietary Diversity (MDD): the proportion of children aged 623 months who receive foods from four or more food groups during the previous day; (2) Minimum Meal Frequency (MMF): the proportion of breastfed and non-breastfed children aged 6-23 months who receive solid, semi-solid or soft foods the minimum number of times or more (minimum is defined as: two times for breastfed infants 6-8 months; three times for breastfed children 9-23 months; and four times for nonbreastfed children 6-23 months) in the previous day; (3) Minimum Acceptable Diet (MAD): the proportion of breastfed children aged 6-23 months who had at least the MDD and the MMF during the previous day, and non-breastfed children who received at least two milk feedings and had at least the MDD (not including milk feeds) and the MMF during the previous day.

\subsection{Statistical analysis}

Epi Data 3.0 was employed for double entry and error detection of data, and SPSS 19.0 software was used for statistical analysis. The results of count data were expressed as rate (\%). The rate comparison between two or more groups was tested by $\chi 2$. Multivariate analysis was performed by unconditional logistic regression. If $\mathrm{P}<0.05$, then the difference was statistically significant.

\section{Results}


425 children (34.8\%) were investigated in high-income areas, $412(33.8 \%)$ in middle-income areas and $383(31.4 \%)$ in low-income areas; a total of 1220 children were surveyed, including 608 boys (49.8\%) and 612 girls (50.2\%); 417 (34.2\%) children were aged 6-11 months, 407 (33.4\%) were aged 12-17 months and $396(32.5 \%)$ were aged $18-23$ months. The vast majority $(1121,91.9 \%)$ of children surveyed were of Han nationality; 706 (57.9\%) were non-left-behind and non-migrant children, 15 were migrant children (1.2\%) (Table 1).

Table 1 Basic situation of children aged 6 to 23 months

\begin{tabular}{|c|c|c|c|}
\hline Characteristics & & Frequency & Percent(\%) \\
\hline \multirow[t]{3}{*}{ Regional economic level } & High-income areas & 425 & 34.8 \\
\hline & Middle-income areas & 412 & 33.8 \\
\hline & Low-income areas & 383 & 31.4 \\
\hline \multirow[t]{2}{*}{ Sex of the child } & Male & 608 & 49.8 \\
\hline & Female & 612 & 50.2 \\
\hline \multirow[t]{3}{*}{ Age of the child (months) } & $6-11$ & 417 & 34.2 \\
\hline & $12-17$ & 407 & 33.4 \\
\hline & $18-23$ & 396 & 32.5 \\
\hline \multirow[t]{2}{*}{ Nationality } & Han nationality & 1121 & 91.9 \\
\hline & Non Han nationality & 99 & 8.1 \\
\hline \multirow[t]{4}{*}{ Children's category } & Non-left-behind and non-migrant children & 706 & 57.9 \\
\hline & Migrant children & 15 & 1.2 \\
\hline & Single left-Behind Children & 295 & 24.2 \\
\hline & Left-behind children & 203 & 16.6 \\
\hline \multirow[t]{3}{*}{ Birth weight } & Normal & 1124 & 92.13 \\
\hline & low-birth-weight & 47 & 3.85 \\
\hline & Overweight & 49 & 4.02 \\
\hline \multirow[t]{2}{*}{ Birth order } & Preterm & 70 & 5.74 \\
\hline & Full-term & 1150 & 94.26 \\
\hline \multirow[t]{2}{*}{ Pregnancy } & Singleton & 1177 & 96.63 \\
\hline & Multiples & 41 & 3.67 \\
\hline
\end{tabular}


The average age of surveyed mothers was 29.85 years. The educational background of them was mainly junior high school and below (45.3\%), and they were chiefly engaged in agriculture (43.4\%). The education background of fathers was mainly junior high school and below (45.7\%). Most of the caregivers $(834,67.4 \%)$ were mothers and primarily engaged in agriculture $(65.8 \%)$. The education background of caregivers(59.3\%) was mainly junior high school and below, followed by high school/technical secondary school (25.2\%). Most of the families' annual total income was 60,000 yuan and above (746, 61.1\%), and most of them spent 6000 yuan and above for food (920, 75.4\%). Most (996, $81.6 \%$ ) mothers did not go out for working; $58.3 \%$ of the families have two children and most (54.9\%) of the investigated children were the second child in the family(Table 2).

2.3 Basic public health services

Table 2 Characteristics of family and social demographics of children aged 6 to 23 months 


\begin{tabular}{|c|c|c|c|}
\hline Characteristics & & Frequency & Percent(\%) \\
\hline \multirow[t]{4}{*}{ Age of the mother (years) } & $<25$ & 178 & 14.6 \\
\hline & $25-29$ & 400 & 32.8 \\
\hline & $30-34$ & 435 & 35.7 \\
\hline & $\geq 35$ & 207 & 17.0 \\
\hline \multirow[t]{5}{*}{ Maternal education } & Junior high school and below & 553 & 45.3 \\
\hline & High school/Technical & 372 & 30.5 \\
\hline & Secondary school & & \\
\hline & College & 195 & 16.0 \\
\hline & University or above & 100 & 8.2 \\
\hline \multirow[t]{5}{*}{ Maternal occupation } & Agriculture & 529 & 43.4 \\
\hline & Government Employer & 209 & 17.1 \\
\hline & Specialist & 145 & 11.9 \\
\hline & Service worker & 52 & 4.3 \\
\hline & Other & 285 & 23.4 \\
\hline \multirow[t]{5}{*}{ Paternal education } & Junior high school and below & 558 & 45.7 \\
\hline & High school/Technical & 395 & 32.4 \\
\hline & Secondary school & & \\
\hline & College & 150 & 12.3 \\
\hline & University or above & 114 & 9.3 \\
\hline \multirow[t]{5}{*}{ Paternal occupation } & Agriculture & 90 & 7.4 \\
\hline & Government Employer & 131 & 10.7 \\
\hline & Specialist & 325 & 26.6 \\
\hline & Service worker & 255 & 20.9 \\
\hline & Others & 416 & 34.1 \\
\hline \multirow[t]{3}{*}{ Primary caregiver } & Monther & 834 & 68.4 \\
\hline & Father & 16 & 1.3 \\
\hline & Other & 370 & 30.3 \\
\hline Caregivers education & Junior high school and below & 724 & 59.3 \\
\hline
\end{tabular}




\begin{tabular}{|c|c|c|c|}
\hline & $\begin{array}{l}\text { High school/Technical } \\
\text { Secondary school }\end{array}$ & 308 & 25.2 \\
\hline & College & 131 & 10.7 \\
\hline & University or above & 54 & 4.4 \\
\hline \multirow[t]{5}{*}{ Caregivers occupation } & Agriculture & 803 & 65.8 \\
\hline & Government Employer & 113 & 9.3 \\
\hline & Specialist & 72 & 5.9 \\
\hline & Service worker & 61 & 5.0 \\
\hline & Other & 167 & 13.7 \\
\hline \multirow[t]{2}{*}{ Migrant mother or not } & Migrant mother & 217 & 17.8 \\
\hline & Non-migrant mother & 996 & 81.6 \\
\hline \multirow[t]{4}{*}{ Annual family income(yuan) } & $<20000$ & 43 & 3.5 \\
\hline & $20000-30000$ & 141 & 11.6 \\
\hline & $40000-50000$ & 290 & 23.8 \\
\hline & $\geq 60000$ & 746 & 61.1 \\
\hline \multirow[t]{4}{*}{ Annual expenses on food } & $<2000$ & 20 & 1.6 \\
\hline & 2000-3999 & 110 & 9.0 \\
\hline & $4000-5999$ & 169 & 13.9 \\
\hline & $\geq 6000$ & 920 & 75.4 \\
\hline \multirow[t]{2}{*}{ Poor household or not } & Non-poor housebold & 1163 & 95.3 \\
\hline & Poor household & 48 & 3.9 \\
\hline \multirow[t]{2}{*}{ Low-income household } & Non-Low-income household & 1193 & 97.8 \\
\hline & Low-income household & 21 & 1.7 \\
\hline \multirow[t]{3}{*}{ The number of children in the family } & One child & 378 & 31.0 \\
\hline & Twe children & 711 & 58.3 \\
\hline & Three or more children & 131 & 10.7 \\
\hline \multirow[t]{3}{*}{ Birth order } & First & 441 & 36.1 \\
\hline & Second & 670 & 54.9 \\
\hline & Third and above & 109 & 8.9 \\
\hline
\end{tabular}


The utilisation of basic public health services for children was evaluated. The vast majority of children received free physical examination (90.6\%), free height and weight measurement (90.5\%) and free haemoglobin test (81.6\%) (Table 3).

Table 3 Health care services for children aged 6 to 23 months

\begin{tabular}{|llll|}
\hline Characteristics & & Frequency & Percent(\%) \\
\hline Free physical examination & Non-examined children & 103 & 9.4 \\
\hline $\begin{array}{l}\text { Free height and weight } \\
\text { measurement }\end{array}$ & Cxamined children & 1105 & 90.6 \\
\hline Children without measurement & 105 & 9.5 \\
\hline Free haemoglobin test & Children receiving measurement & 1104 & 90.5 \\
\hline & $\begin{array}{l}\text { Children without free haemoglobin } \\
\text { test } \\
\text { Children receiving free haemoglobin } \\
\text { test }\end{array}$ & 192 & 18.4 \\
\hline
\end{tabular}

2.4 Knowledge and attitude towards nutrition and health of parents

Results of the survey showed that most parents $(67.7 \%)$ had scores of 80 or above on knowledge and attitude towards nutrition and health, and only very few (6.8\%) failed. This finding indicated that most parents have certain knowledge of feeding and nutrition(Table 4).

Table 4 Knowledge and attitudes towards nutrition and health of parents

\begin{tabular}{|llll|}
\hline Characteristic & & Frequency & Percent(\%) \\
\hline Knowledge and attitude towards nutrition and health & $<60$ scores & 83 & 6.8 \\
\hline & $60-79$ scores & 311 & 25.5 \\
\hline & $80-100$ scores & 826 & 67.7 \\
\hline
\end{tabular}

\subsection{Complementary food}

For complementary food, the proportion of cereals was high (93.1\%), and the proportion of white potatoes, dark vegetables, fruits and red potatoes, dairy products, beans and soy products and nuts were low $(<50 \%)$. The proportion of nuts added was only $14.4 \%$. About $4.3 \%, 32.3 \%, 21.2 \%, 24.0 \%, 25.0 \%$, $61.6 \%$ and $56.6 \%$ of the survey respondents aged $18-23$ months were not fed with cereals and grains, fruits and vegetables rich in vitamin A, other fruits and vegetables, fresh foods, eggs, dairy products, legumes and nuts. With increasing age of month, the addition rate of various complementary foods showed an upward trend $(P<0.05$, Table 5$)$. 
Table 5 Comparison of proportion of complementary food

\begin{tabular}{|c|c|c|c|c|c|c|}
\hline Proportion & $\begin{array}{l}\text { 6-11 } \\
\text { months }\end{array}$ & $\begin{array}{l}12-17 \\
\text { months }\end{array}$ & $\begin{array}{l}18-23 \\
\text { months }\end{array}$ & Total & Trend $c^{2}$ & $P$ \\
\hline Cereals and grains & $79.4 \otimes 331 \rrbracket$ & $92.1 \otimes 375 \rrbracket$ & $95.7 \rrbracket 379 \rrbracket$ & $\begin{array}{l}88.9 \\
\text { ه1085】 }\end{array}$ & 55.545 & $<0.001$ \\
\hline $\begin{array}{l}\text { VA rich fruits and } \\
\text { vegetables }\end{array}$ & $37.6 \otimes 157 \rrbracket$ & $61.2 \varangle 249 \rrbracket$ & $67.7 \rrbracket 268 \rrbracket$ & $\begin{array}{l}55.2 \\
\square 674 \rrbracket\end{array}$ & 74.749 & $<0.001$ \\
\hline $\begin{array}{l}\text { Other fruits and } \\
\text { vegetables }\end{array}$ & $46.8 \otimes 195 \rrbracket$ & $73.0 \rrbracket 297 \rrbracket$ & $78.8 \rrbracket 312 \rrbracket$ & $\begin{array}{l}65.9 \\
\square 804 \rrbracket\end{array}$ & 93.668 & $<0.001$ \\
\hline Flesh foods & $31.2 \otimes 130 \rrbracket$ & $63.1 \otimes 257 \rrbracket$ & $76.0 \otimes 301 \rrbracket$ & $\begin{array}{l}56.4 \\
\bigotimes 688 \rrbracket\end{array}$ & 167.156 & $<0.001$ \\
\hline Eggs & $50.8 \rrbracket 212 \rrbracket$ & $72.5 \rrbracket 295 \rrbracket$ & $75.0 \otimes 297 \rrbracket$ & $\begin{array}{l}65.9 \\
\square 804 \rrbracket\end{array}$ & 53.454 & $<0.001$ \\
\hline Diary product & $7.7 \rrbracket 32 \rrbracket$ & $54.8 \otimes 101 \rrbracket$ & $38.4 \rrbracket 152 \rrbracket$ & $\begin{array}{l}23.4 \\
\rrbracket 285 \rrbracket\end{array}$ & 107.146 & $<0.001$ \\
\hline Legumes and nuts & $10.6 \rrbracket 44 \rrbracket$ & $29.0 \bigotimes 118 \rrbracket$ & $43.4 \rrbracket 172 \rrbracket$ & $\begin{array}{l}27.4 \\
\rrbracket 334 \rrbracket\end{array}$ & 110.629 & $<0.001$ \\
\hline
\end{tabular}

2.6 Evaluation indicators

The evaluation indicators of complementary feeding were assessed. About $62.3 \%$ of the caregivers provided their children with four or more types of foods that met the MDD the day before the survey. Meanwhile, about three-quarters $(75.1 \%)$ of the caregivers provided their children with food before the survey that achieved the MMF. Hence, the eligibility rate of the MAD of children was $44.0 \%$.

\subsection{Univariate and multivariate analyses}

Children were grouped according to their basic conditions, family sociodemographic characteristics, basic public health services, knowledge and attitude of parents towards nutrition and health. The eligibility rates of MDD, MMF and MAD among the groups were compared. Statistically significant variables were selected through single-factor analysis, and they included month age of children, survey areas, mothers moving out to work or not, and scores of parents of knowledge of nutrition and health. With MDD, MMF and MAD as dependent variables (eligible=0; unqualified=1), the statistically significant variables of the univariate analysis were incorporated into the multivariate logistic regression model for multivariate analysis. The results showed that young month-age of infants was a risk factor for ineligible MDD and MAD. Compared with the 6-11-month-old group, the probability of ineligible MDD of 12-17month-old group was about one-quarter ( $\mathrm{OR}=0.238,95 \%: 0.177-0.320)$, and the probability of ineligible MAD was one-half (OR=0.425,95\%:0.317-0.517). The probability of ineligible MDD in the 18-23-monthold group was only one-tenth (OR=0.103,95\%:0.074-0.145), and the probability of ineligible MAD was one-third (OR=0.376,95\%:0.279-0.507). Low score of parents with regard to knowledge of nutrition and 
health was a risk factor for ineligible MDD, MMF and MAD for children. Compared with the group whose scores were $<60$, the probability of ineligible MDD, MMF and MAD in the group of 60-79 scores were about two-thirds, and that in the group of 80-100 scores were about one-half. The survey area was related to the disqualification of MDD, MAD and MAD. The failure rate of MMF was higher in the group of mothers that did not go out for work compared with that in the group of migrant mothers (Table 6).

Table 6 Multivariate logistic regression analysis of complementary feeding [OR(95\% Cl) value] 


\begin{tabular}{|c|c|c|c|}
\hline Variables & Ineligible MDD & Ineligible MMF & Ineligible MAD \\
\hline \multicolumn{4}{|c|}{ Age of the child (months) } \\
\hline $6-11$ & 1 & & 1 \\
\hline $12-17$ & $\begin{array}{l}0.238(0.177- \\
0.320)\end{array}$ & & $\begin{array}{l}0.425(0.317- \\
0.517)\end{array}$ \\
\hline $18-23$ & $\begin{array}{l}0.103(0.074- \\
0.145)\end{array}$ & & $\begin{array}{l}0.376(0.279- \\
0.507)\end{array}$ \\
\hline \multicolumn{4}{|l|}{ Survey area } \\
\hline Changsha County & 1 & 1 & 1 \\
\hline Ningxiang County & $\begin{array}{l}1.590(0.839- \\
3.013)\end{array}$ & $\begin{array}{l}2.939(1.508- \\
5.727)\end{array}$ & $\begin{array}{l}1.941(1.113- \\
3.384)\end{array}$ \\
\hline Chaling County & $\begin{array}{l}1.686(0.889- \\
3.199)\end{array}$ & $\begin{array}{l}0.927(0.415- \\
2.073)\end{array}$ & $\begin{array}{l}1.066(0.608- \\
1.869)\end{array}$ \\
\hline Youxian County & $\begin{array}{l}2.119(1.118- \\
4.013)\end{array}$ & $\begin{array}{l}1.160(0.547- \\
2.459)\end{array}$ & $\begin{array}{l}1.897(1.086- \\
3.315)\end{array}$ \\
\hline Xiangyin County & $\begin{array}{l}2.024(1.058- \\
3.872)\end{array}$ & $\begin{array}{l}1.468(0.712- \\
3.030)\end{array}$ & $\begin{array}{l}1.938(1.097- \\
3.422)\end{array}$ \\
\hline Pingjiang County & $\begin{array}{l}2.214(1.174- \\
4.174)\end{array}$ & $\begin{array}{l}2.734(1.396- \\
5.353)\end{array}$ & $\begin{array}{l}2.444(1.394- \\
4.286)\end{array}$ \\
\hline Taojiang County & $\begin{array}{l}2.006(1.054- \\
3.818)\end{array}$ & $\begin{array}{l}3.844(1.984- \\
7.446)\end{array}$ & $\begin{array}{l}3.733(2.065- \\
6.750)\end{array}$ \\
\hline Anhua County & $\begin{array}{l}2.368(1.270- \\
4.416)\end{array}$ & $\begin{array}{l}3.436(1.792- \\
6.589)\end{array}$ & $\begin{array}{l}3.673(2.088- \\
6.462)\end{array}$ \\
\hline Longhui County & $\begin{array}{l}1.694(0.832- \\
3.450)\end{array}$ & $\begin{array}{l}1.267(0.548- \\
2.925)\end{array}$ & $\begin{array}{l}1.423(0.755- \\
2.682)\end{array}$ \\
\hline Dongkou County & $\begin{array}{l}3.330(1.784- \\
6.217)\end{array}$ & $\begin{array}{l}3.303(1.717- \\
6.354)\end{array}$ & $\begin{array}{l}4.050(2.271- \\
7.221)\end{array}$ \\
\hline Xinguang County & $\begin{array}{l}1.720(0.880- \\
3.360)\end{array}$ & $\begin{array}{l}1.602(0.767- \\
3.346)\end{array}$ & $\begin{array}{l}2.701(1.510- \\
4.832)\end{array}$ \\
\hline Xupu County & $\begin{array}{l}1.065(0.560- \\
2.025)\end{array}$ & $\begin{array}{l}1.251(0.612- \\
2.556)\end{array}$ & $\begin{array}{l}1.649(0.961- \\
2.830)\end{array}$ \\
\hline \multicolumn{4}{|l|}{ Migrant mother or not } \\
\hline Migrant mother & & 1 & \\
\hline Non-migrant mother & & $\begin{array}{l}2.069(1.364- \\
3.139)\end{array}$ & \\
\hline
\end{tabular}




\begin{tabular}{|llll|} 
<60scores & 1 & 1 & 1 \\
\hline $60-79$ scores & $0.653(0.377-$ & $0.689(0.402-$ & $0.668(0.384-$ \\
& $1.130)$ & $1.180)$ & $1.160)$ \\
\hline $80-100$ scores & $0.543(0.325-$ & $0.428(0.256-$ & $0.496(0.295-$ \\
& $0.909)$ & $0.715)$ & $0.834)$ \\
\hline
\end{tabular}

\section{Discussion}

Studies have reported no significant difference in the growth rate of height and weight of children within 6 months between China and developed countries. the growth curve of Chinese infants within 6 months is close to the standard curve recommended by the WHO. However, the growth curve after 6 months gradually lag behind primarily due to improper addition of complementary food ${ }^{[10]}$.In the present study, according to Programming Guide: Infant and Young Child Feeding ${ }^{[11]}$ by the WHO, the eligibility rate of MDD, MMF and MAD were used to evaluate the status of complementary feeding of children aged 6-23 months in rural areas of Hunan Province.

Compared with the feeding indicators of 46 developing countries ${ }^{[12]}$ reported by the WHO and UNICEF in 2010, the eligibility rate of MDD, MMF and MAD in the present study are 15th, 8th and 6th respectively, which are at the optimum level. The eligibility rate of MDD, MMF and MAD in this study are generally better than the data reported in all China ${ }^{[13]}$, central and western regions ${ }^{[14]}$ and Xinjiang ${ }^{[15]}$, but lower than the data reported in Hubei Province ${ }^{[16]}$. Since 2012, some rural areas in Hunan Province have participated in the national Projects on Children Nutrition Improvement in Poor Areas ${ }^{[17]}$ that provide children aged 6-23 months with a packet of nutrients rich in protein, vitamins and minerals. At the same time, health education on nutrition was carried out to improve family members' feeding knowledge in rural areas, and complementary feeding has been promoted.

This study shows that most children aged 6-23 months were fed with complementary foods, but the types of foods were too single, mainly cereals and grains, and other types of foods were rarely added, especially dairy products, legumes and nuts. Even for children aged 18-23 months, the addition rate was less than $50 \%$, and the intake of high-quality protein and micronutrients was insufficient. Based on the recommendations of the American Academy of Paediatrics, the European Society for Paediatric Gastroenterology, Hepatology and Nutrition ${ }^{[18]}$ and related food guide for infants and young children in British and Australia ${ }^{[19]}$, diverse food should be added. Complementary food in rural areas was mainly prepared by the family, mostly by grandparents, the dietary structure was unreasonable, which mainly included cereals, low amounts of fruits and vegetables and insufficient high-quality animal food due to the limited nutritional knowledge.

This study shows that young month-age, mothers' not going out to work and parents' lacking in knowledge about nutrition and health were high risk factors for ineligible complementary feeding. 
The eligibility rates of MDD and MAD were the lowest in the group of infants aged 6-11 months. The addition of complementary foods for children is assumed to be a process that is gradually accepted. As the months of age of children increase, their digestive systems will be more perfectly developed, which means that more types of foods can be accepted, leading to a more reasonable dietary structure. Children aged 6-11 months required the highest nutrient density and was the most prone to lack trace elements. During this period, consuming various iron-rich foods is essential to meet the high nutritional needs (especially iron and zinc, which are common deficiencies) ${ }^{[20]}$. A relatively small difference in complementary feeding was found between the groups of 12-17 months and 18-23 months, where the eligibility rate of MDD nearly doubled from 6-11 months to 12-17 months, and that of MAD increased by $21.8 \%$. Early dietary diversity of children is closely related to their subsequent growth and development ${ }^{[21]}$. Studies have shown that the risk of stunting in children with qualified complementary feeding is significantly reduced ${ }^{[22]}$. The younger the children is, the greater their developmental potential will be. Therefore, attention should be paid to the complementary feeding of children at young month age and the types of food should be increased as soon as possible to meet the dietary requirements so children can achieve their maximum potential.

The eligibility rates of MDD, MMF and MAD in different surveyed areas were different. Differences in culture, economic status and knowledge level in different areas may affect the complementary feeding of infants and young children in the area. For example, the eligibility rate of various indicators of complementary feeding in Changsha was at a relatively high level, which was assumed to be due to the higher level of economic development and living standard of people in this area, leading to more money and energy invested in feeding of children.

The eligibility rate of MMF for children whose mothers were migrant workers was higher than that of children whose mothers were not migrant workers. It's speculated that children whose mothers were migrant workers were generally raised by their grandparents who have certain experience in raising children and are more familiar with the characteristics of each growth stage of children. Therefore, they can provide diverse and sufficient complementary food. Moreover, grandparents tend to treat their grandchildren more lovingly and patiently, which is good for communication and a harmonious family atmosphere where children can take more suitable food.

This finding indicated that the higher the score of parents' knowledge and attitudes towards nutrition and health is, the higher the eligibility rates of MDD, MMF and MAD and the better complementary feeding for children. A study conducted in five South Asian countries showed that caregivers' lacking knowledge in feeding was the main reason for inappropriate complementary feeding ${ }^{[23]}$. Other studies have shown similar results ${ }^{[24]}$.

\section{Conclusion}

The study shows that types of complementary food in rural areas of China were too single and children's dietary structure was unreasonable which needed to be improved. Young month-age, mothers' not going 
out to work and parents' lacking in knowledge about nutrition and health were high risk factors for ineligible complementary feeding.When analysing the results of this study, some design limitations should be considered. First of all, this study was a cross-sectional survey, it can only confirm the correlation between factors and results and not the causality. Secondly, this study assessed the complementary feeding at a certain time point while ignoring the possible changes in complementary feeding as the child grows up. That is to say, the current condition of complementary feeding can neither represent its previous condition nor predict the situation afterwards.

\section{Abbreviations}

MDD: Minimum dietary diversity

MMF: Minimum meal frequency

MAD: Minimum acceptable diet

WHO: World Health Organization

UNICEF: United Nations International Children's Emergency Fund

\section{Declarations}

Ethics approval and consent to participate: We were approved by the ethics committee of the Hunan Provincial Maternity and Child Health Hospital, and an informed consent form was signed by the caregivers of the subjects before the investigation.

Consent for publication: Not applicable.

Availability of data and materials: The datasets used and/or analysed during the current study are available from the corresponding author on reasonable request.

Competing interests: The authors declare that they have no competing interests.

Funding: Not applicable.

Authors' contributions: HG conceived the idea of the study; LH and LX analysed the data; HQ interpreted the results; LM wrote the paper; all authors discussed the results and revised the manuscript.

Acknowledgements: Not applicable.

\section{References}

[1] UNICEF, WHO, World Bank Group. Joint child malnutrition estimates. New York: UNICEF; Geneva: WHO; Washington DC: World Bank Group; 2020. Avaliable from https://www.who.int/news-room/detail/31-03- 
2020-unicef-who-wb-jme-group-new-data.

[2] WHO. World health statistics 2015. Geneva: The Organization; 2015. Avaliable from http://apps.who.int/iris/bitstream/10665/170250/1/9789240694439_eng.pdf?ua=1 \&ua=1.

[3] Black RE, Victora CG, Walker SP, et al. Maternal and child undernutrition and overweight in low-income and middle-income countries. J. Lancet. 2013;382(9890):1-15.

[4] Dewey KG. Reducing stunting by improving maternal, infant and young child nutrition in regions such as South Asia: evidence, challenges and opportunities. J. Matern. Child. Nutr. 2016;12(1):27-38.

[5] Shelley MG. World Health Organization. Comprehensive implementation plan on maternal, infant, and young child nutrition. Geneva, Switzerland. J. Adv. Nutr. 2014;6(1):134-35.

[6] Chapagain RH. Factors affecting complementary feeding practices of Nepali mothers for 6 months to 24 months children. J. Nepa. Health. Res. Counc. 2013;11(24):205-07.

[7] Gessese D, Bolka H, Abajobir AA, Tegabu D. The practice of complementary feeding and associated factors among mothers of children 6-23 months of age in Enemay district, Northwest Ethiopia. J. Food. Sci. Nutr. 2014;44(3):230-40.

[8] Tessema M, Belachew T, Ersino G. Feeding patterns and stunting during early childhood in rural communities of Sidama, South Ethiopia. Pan. Afr. Med. J. 2013;14:75.

[9] Mitchodigni IM, Hounkpatin WA, Ntandou-Bouzitou G et al. Complementary feeding practices: determinants of dietary diversity and meal frequency among children aged 6-23 months in Southern Benin. J. Food. Secur. 2017;9:1117-30.

[10] Michaelsen KF, Friis H. Complementary feeding: A global perspective. J. Nutrition. 1998; 14(10):76366.

[11] WHO, UNICEF, USAID, et al. Indicators for assessing infant and young child feeding practices: Partヌ:Definitions. Geneva: WHO; New York: UNICEF; Washington DC: USAID; 2007. Avaliable from https://apps.who.int/iris/bitstream/handle/10665/43895/9789241596664_eng.pdf? sequence=1 .

[12] WHO, UNICEF, USAID, et al. Indicators for assessing infant and young child feeding practices: Part III : Country Profiles. Geneva: WHO; New York: UNICEF; Washington DC: USAID; 2010. Avaliable from https://apps.who.int/iris/bitstream/handle/10665/44368/97892415 99757_eng.pdf?ua=1.

[13] Duan Yf, Yang ZY, Lai JQ, et al. Exclusive breastfeeding rate and complementary feeding indicators in China: a national representative survey in 2013. J. Nutrients. 2018;10(2):249.

[14] Feng $Y$, Zhou H, Wang XL, Zhang JX, Wang Y. Study of the infant and young child feeding practice in some areas of China and across-country comparison. Chin. J. Child. Health. care. 2012;20(8):689-92.(In 
Chinese)

[15] Zhang $\mathrm{H}$, Zhang $\mathrm{H}$, Chen $\mathrm{H}$, Dong J. Analysis of the status and related factors for complementary feeding of 6 to 23-month-old infants in Xinjiang. Chin. J. Child. Health. Care. 2019;27(11):1183- 87.(In Chinese)

[16] Liu S, Li J, Gong C, Cheng M, Song Y. Evaluation of the feeding status of infants and young children under 2 years old in rural areas of Hubei province. Chin. J. Prev. Med. 2014; 48(8):705-09.

[17] Xu J, Huo JS, Sun J, Huang J. Complementary food supplements interventions for 6 to 24 months old infants in poverty areas. Chin. J. Food. Hyg. 2017;29(5):550-55.(In Chinese)

[18] Fewtrell M, Bronsky J, Campoy C, et al. Complementary feeding: A position paper by the European Society for Paediatric Gastroenterology, Hepatology, and Nutrition (ESPGHAN) Committee on Nutrition. J. Pediatr. Gastroenterol. Nutr. 2017;64(1):119-32.

[19] National Health and Medical Research Council. Infant Feeding Guidelines. Canberra: National Health and Medical Research Council; 2012. Avaliable from www.nhmrc.gov.au/guidelines-publications/n56.

[20] Dewey KG. The challenge of meeting nutrient needs of infants and young children during the period of complementary feeding: An evolutionary perspective. J. Nutr. 2013;143(12):2050-54.

[21] Mallard SR, Houghton LA, Filteau S, et al. Dietary diversity at 6 months of age is associated with subsequent growth and mediates the effect of maternal education on infant growth in urban Zambia. J. Nutr. 2014;144(11):1818-25.

[22] Jones AD, Ickes SB, Smith LE, et al. World Health Organization infant and young child feeding indicators and their associations with child anthropometry: A synthesis of recent findings. J. Matern. Child. Nutr. 2013;10(1):1-17.

[23] Senarath U, Agho KE, Akram DE, et al. Comparisons of complementary feeding indicators and associated factors in children aged 6-23 months across five South Asian countries. J. Matern. Child. Nutr. 2012;8(1):89-106.

[24] Mitchodigni IM, Hounkpatin WA, Ntandou-Bouzitou G, et al. Complementary feeding practices: determinants of dietary diversity and meal frequency among children aged 6-23 months in Southern Benin. J. Food. Sec. 2017;9:1117-30. 